\title{
ACTUALIDADES
}

Rev. Chll. Pedlatr. 68 (1); 27-37, 1997

\section{Sistema hormona del crecimiento-efector y su rol en el crecimiento infantil}

\author{
Verónica Mericq G. ${ }^{1}$; Fernando Cassorla G. ${ }^{1}$
}

\begin{abstract}
Resumen
La consula por retroso del crecimiento es muy frecuente en pediatric. En to úlimo década se han efectuado importantes avances en la comprensión de los mecanismos hormoncles que regulan el crecímiento infantil. Este articulo liente por abjec hocer uno acivalización sobre el sistema hormona de crecimiento KGH'fefector. Se revison los mecanismos de conlrol hipctatamico de la secreción de GH (lactor liberador de GH y somatostatinal. secreción hipofisiaria de $\mathrm{GH}$, lo proteina ligadora de $\mathrm{GH}$ [GHBPI, el recepicr de $\mathrm{GH}$ y sus efectores periféricos $\|$ GFs e IGF3PS. Se onalizon ias repercusiones clinicas de las alteraciones de cado uno de estos componentes, que pueden conducir a una falla en e! crecimienlo duronte lo infancia.
\end{abstract}

(Palabras clave: crecimiento, receptores de hcrmona de crecimiento.)

\section{Growth hormone-effector systems role in children's growth}

Growt failure is a frequent occurrence pedialrics. During the last decade trere nave been important advonces in our undersianding of the hormonal mechanisms which regulole growth during childhood. The gool of this article is to offer an updake zoout the growth homorie IGHrelector system. We review the mechanisms which underlie the ryfothalamic control of growth hormone secretion [ $\mathrm{GH}$ :eleasing factor and somatoslatin], piluilary secrericn of $\mathrm{GH}$, $\mathrm{GH}$ binding protein $1 \mathrm{GHEP}$. GH recesto and is seripheral electors (IGFs and IGFBPS). We anolize the elinicai consequences of cbnormalities in this sysiem, which can lead 10 growth falure during childhood.

[Key words: growth, growh harmone receptors.]

La consulta por retraso del crecimiento es muy frecuente en pediatría. Este artículo tiene por objeto hacer una actualización sobre los avances en nuestra comprensión sobre el sistema hormona de crecimiento-efector. Esta revjsión es necesaria, ya que para evaluar un niño que consulta por talla baja es importante conocer los mecanismos fundamentales que son responsables del crecimiento infantil.

Las causas de baja estatura más frecuentes son las llamadas "variantes normales del crecimiento". Estas corresponden fundamentalmente a la talla baja familiar y al retraso constitucional

I. Instituto de Inyestigaciones Materno Infantil, Facultad Je Medicina, Campus CenIro. Cniversidad de Chile. Finauciado en pane por proyecto Fondecyt 1940543. del crecimiento. En el primer caso existen claros antecedentes familiares de baja estatura y la curva de crecimiento tiende a ser inferior pero paralela al percentil 5 . En el segundo caso existe una historia familiar de retraso del desarrollo puberal y la curva de crecimiento tiende a desviarse por debajo del percentil 5 a partir del segundo año de vida. La edad ósea es concordante con la cronologica en la tálla baja familiar $y$ es menor en el retraso constitucional. Debido a ello, el pronóstico de talla tiende a ser superior en los casos constitucionales. Cabe mencionar que, en algunos pacientes, ambos cuadros clíni$\cos$ pueden coexistir, lo que puede acentuar el retardo de la talla.

Otras causas de retraso del crecimiento incluyen una variedad de enfermedades sistémicas que pueden afectar a diversos órganos, altera- 
ciones nutricionales, anomalía de los cromosomas como la del sindrome de Turner, displasias oseas de diversos tipos $-q u e$ a veces pueden ser sutiles- y retraso del crecimiento intrauterino. Las enfermedades del sistema endocrino que pueden causar talla baja son Ias alteraciones del sistema hormona de crecimiento-efector, el hipotitoidismo y el hipercortisolismo. En estos casos, la curva de crecimiento muestra importante desviación por debajo del canal de crecimiento previo y la edad ósea está muy atrasada. En el hipercortisolisno existe además significativa ganancia de peso asociada a la talla baja. Los elementos clínicos y de laboratorio más fundamentales para evaluar a un paciente con retraso del crecimiento son la cuidadosa anamnesis personal y familiar, que incluya el estudio de la curva de peso y de talla; un completo examen físico con especial atención al fenotipo y a las proporciones de los segmentos corporales; exámenes generales (hemograma, perfil bioquímico, caroteno, orina, coproparasitologico) y la radiografía de mano para determinar la edad ósea. Con estos elementos es posible efectuar un diagnóstico etiológico en la mayoría de los pacientes con talla baja. En la figura 1 se muestra un esquema de orientación al diagnóstico en un niño con talla baja.
Diversas hormonas están involucradas en la regulación del crecimiento. El eje de la hormona de crecimiento-efector es fundamental durante la niñez y adolescencia y debe funcionar en forma óptima para que las personas alcancen una talla final normal. En los años más recientes nuestro conocimiento sobre este sistema ha aumentado notablemente debido al descubrimiento de numerosos factores que participan en él. Su esquema simplificado se muestra en la figura 2, mientras en la tabla 1 se describen sus componentes.

\section{Hipotálamo}

La secreción de hormona de crecimiento (GH) por la hipófisis anterior es el resultado de la interacción de dos péptidos hipotalámicos: el factor liberador de $\mathrm{GH}$ o $\mathrm{GHRH}^{\prime}$ y la somatostatina o factor inhibidor. La interacción recíproca entre ambos sobre los somatotropos pituitarios determina la pulsatilidad de la secreción de GH. Esta intermitencia en la secreción de hormona de crecimiento hace que la medición de sus concentraciones plasmáticas basales no sea muy útil, ya que tienden a ser bajas. Por este

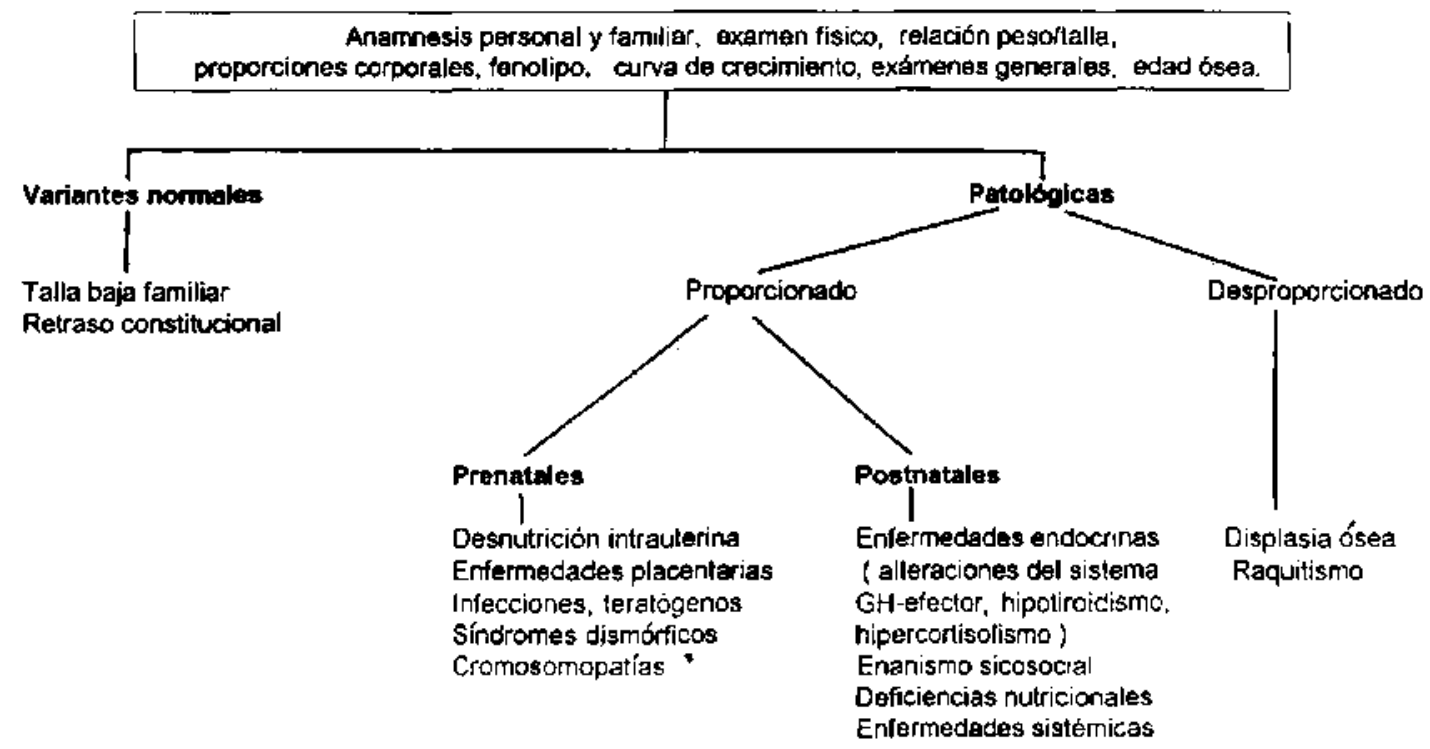

Figura 1: Esquemo básico de orientación diagnóstica para un niño que consulta por baja estatura. 
motivo se han diseñado estrategias para establecer el diagnóstico de deficiencia de $\mathrm{GH}$ estimulando su secreción con diversos fármacos que aciúen modulando la secreción de factor liberador o la de somatostatina. De esta manera se puede evaluar la reserva hipofisiaria para la secreción de $\mathrm{GH}$ en un niño con tatla baja. Desafortunadamente las pruebas de estímulo para GH dan resultados tan variables que son escasamente reproducibles aun en el mismo individuo $^{2}$. Esta variabilidad parece depender, entre otros factores. de la secreción basal de somatostatina, del estado nutricional, del sexo y del grado de desarrollo puberal de cada sujeto y limita la utilidad de las pruebas de estímulo para evaluar pacientes con baja estatura, pues no hay consenso en los puntos de corte para hacer e] diagnostico. Se ha intentado diagnosticar la deficiencia de $\mathrm{GH}$ midiendo sus concentraciones basales en la sangre por periodos de varias horas o en la orina obtenida de recolecciones, pero la estrategia tampoco ha sido muy exitosa. obligando a buscar otras variables para determinar la función del eje hormona de crecimientoefector $^{3}$.

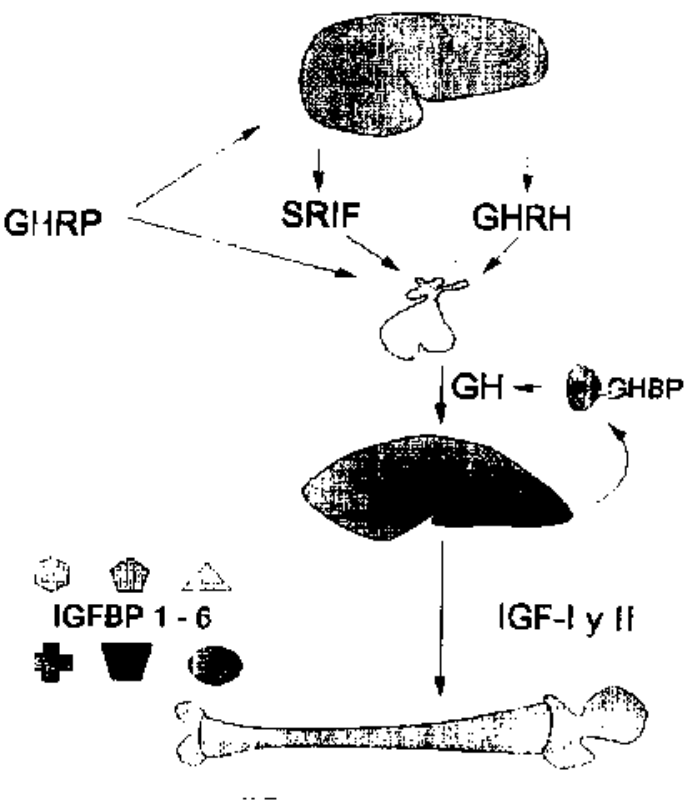

Figura 2: Esquema del sistema hormona del crecimientoefector. GHRP: péptido liberador de hormona de crecimiento: SRIF: somatostatina; GHRH: factor liberador de homona de crecimiento; GHBP: proteina ligadora de hormona de crecimiento; [GF-I y II: factores de crecimienı insulino similes; JGFBP 1-6: proteínas transportadoras de [GFs.

\section{Tabla 1}

Componentes del sistema hormona de crecimiento-efector

\begin{tabular}{|c|c|c|}
\hline Factor & $\begin{array}{l}\text { Localización genética } \\
\text { (cromosama) }\end{array}$ & Descripción \\
\hline Factor liberndor & $7 \mathrm{pl} 4$ & Proteina de 40 y 44 aa \\
\hline Somatostatima & 3 & Proteíra de 14 y $28 "$ \\
\hline Receptor de factor liberador & 6 & Proteína de 401 aa \\
\hline Pl-1 & $3 \mathrm{pll}$ & Proteína de $291 "$ \\
\hline Horınona de clecimiento & 7 & Proteína de $191 "$ \\
\hline Receptor de GH y proteína ligadora de $\mathbf{G H}$ & 5 & Proteína de $610 "$ \\
\hline IGF-I & $12 q$ & \\
\hline IGF-II & IIp & \\
\hline IGF-]r & 15 & Subunid $\alpha 706$ aa: $\beta 626$ aa \\
\hline IGFBPI & $7 p$ & Proteína de 25 a a \\
\hline IGPBP2 & $2 q$ & Proteína de 39 ", \\
\hline IGFBP3 & 7 & Proteína de 27 " \\
\hline KGFBP4 & 17 & Proteína de $21 "$ \\
\hline IGFBP5 & 5 & Proteína de $20 "$ \\
\hline IGFBPG & 12 & Proteina de $27 "$ \\
\hline
\end{tabular}

aa: amiootcido; KG: factor de crecimiento semejante a iosulina; BP: proteína ligante. 


\section{Factor liberador de hormona de crecimiento}

El factor liberador de hormona de crecimiento (GHRH) es un péptido, secretado por el núcleo arcuato del hipotálamo, que pertenece a la familia de los secretores de glucagón. Las proyecciones axonales de las neuronas hipotalámicas de ese núcleo liberan al péptido en el plexo primario del sistema vascular portal pituitario y ejercen su acción sobre los somatotrofos pituitarios. En el hipotálamo humano parecen existir dos formas de GHRH, una de 44 y otra de 40 aminoácidos, aunque la actividad biologica de] péptido radica fundamentalmente en sus primeros 29 aminoácidos ${ }^{4}$, lo que permite utilizar el péptido truncado de 29 aminoácidos como estímulo para la secreción de GH. La función principal del factor liberador de $\mathrm{GH}$ es regular la frecuencia y amplitud de los pulsos de GH. Para que el GHRH hipotalámico pueda ser sintetizado y secretado son fundamentales algunos factores regulatorios de transcripción, tales como las hormonas tiroideas y los glucocorticoides. Asimismo tanto la secreción de somatostatina como del factor liberador están moduladas por una gran variedad de neurotransmisores, otras homonas y factores nutricionales. Algunas de estas substancias sc utilizan como estímulos farmacológicos para determinar la reserva de $\mathrm{GH}$ en los pacientes con talla baja. Sus efectos se presentan en la cabla 2, donde se mencionan aquellas que se utilizan en la práctica clínica como pruebas funcionales para estimular la secreción de GH.

\section{Factor inhibidor de la liberación de hormona de crecimiento}

El facior inhibidor de la liberación de hormona de crecimiento o somatostatina se encontró inicialmente en el núcleo periventricular hipotalámico, pero también se ha aislado del tracto gastrointestinal entre otros tejidos. Es una hormona cuyo efecto es principalmente inhibitorio, no sólo de la secreción de GH, sino también de tirotrofina, insulina y glucagón. Se sabe que su secreción tónica produce niveles basales que pueden variar en un mismo indjviduo $y$ de un individuo a otro. Cuando el tono somatostatinérgico de un niño es elevado, como se observa en los niños con sobrepaso, los niveles de $\mathrm{GH}$ tienden a ser bajos. lo que puede hacer sospechar en forma errónea que padecen de una deficiencia de GH, y lo opuesto ocurre cuando la secreción basal de somatostatina es baja. Sobre este tono nasal de somatostatina ejerce su efecto el factor liberador de $\mathrm{GH}$, lo que determina la frecuencia y amplitud de los pulsos de $\mathrm{GH}$.

Una vez secretados el factor liberador $y$ la somatostatina, ellos unen a sus receptores en los somatotrofos de la adenohipáfisis. El receptor del factor liberador está acoplado a una proteína $G$ estimuladora y en el caso de la somatostatina, el receptor está acoplado a proteína $G$ inhibitoria. Estas proteínas $\mathrm{G}$ están asociadas a diversos receptores de hormonas y su función es activar o inhibir la adenilciclasa, regulando de esta manera los niveles de AMP cíclico intracelular. La

\section{Tabla 2}

Reguladores de la secreción de factor liberador y somatostatina

Factores nutricionales:

Aminoúcidos básicos (arginina)

Hipoglicemia (insulina)

Acidos grasos
Inhiben somatostatina

Inhiben somatostatina

Aumentan somatostatina
Neurotransmisores:

Alfa 2 (clonidina)
Dopauninérgicos (L-dopa)
Colinérgicos
Bela agonistas
Gabaérgicos, serotoninérgicos, hisıaminérgicos
lGF-i y GH

Alfa 2 (clonidina)

Doparninérgicos (L-dopa)

Colinérgicos

Gabaérgicos, serotoninérgiços, hisıaminérgicos IGF-i y GH
Inhiben somnlostatina Inhiben somatostatina Inhiben somatostatina Estimulan somatostatina lnhiben factor liberador Inhiben factor liberador 
unión del factor liberador a su receptor en el somatotropo produce un incremento de los niveles de AMP cíclico y de calcio intracelular. El primero promueve la síntesis de $\mathrm{GH}$, mientras el segundo estimula su secreción.

Existen alteraciones en la secreción del factor liberador de GH y en la función de su receptor que constituyen la causa de la talla baja observada en algunos pacientes con deficiencia de $\mathrm{GH}$. Estos pacientes producen GH en respuesta al factor liberador, lo que demuestra que su defecto reside en el hipotálamo y no en la glándula pituitaria. En un sentido estricto, ellos no son deficientes de $\mathrm{GH}$, ya que su hipófisis es capaz de producirla, sino que les falta el estímulo del factor liberador ${ }^{5}$. Muchos de estos pacientes han sido tratados en forma crónica con factor liberador en lugar de hormona del crecimiento, con buenos resultados. Recientemente se publicó una experiencia mundial con un importante número de pacientes prepuberales deficientes de GH, cuya velocidad de crecimiento aumentó

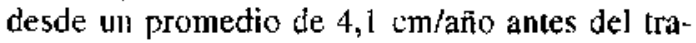
tamiento a $8 \mathrm{~cm} /$ año a los 6 meses y a $7,2 \mathrm{~cm} /$ año a los 12 meses de tratamiento con factor liberador ${ }^{6}$. Nuestro grupo trat $\delta$ a 11 niños prepuberales deficientes de hormona de crecimiento con factor liberador con y sin atenolol, un bloqueador Bl adrenérgico que inhibe la secreción de somatostatina. Los pacientes se trataron durante 2 años en un régimen de doble ciego cruzado $y$ se observó un mayor incremento en la velocidad de crecimiento los tratados con factor liberador $y$ atenolol? ${ }^{7}$. Esto sugiere que se obtienen mejores resultados cuando se estimula la secrecion de $\mathrm{GH}$ con factor liberador y se inhibe la secreción de somatostatina con otro fármaco y demuestra que la terapia con factor liberador puede ser efectiva en muchos niños deficientes de GH. por to que diversos grupos están tratando de simplificarla para optimizar los resultados.

Basándose en la observación que la deficiencia del factor liberador ocurre en más de la mitad de los niños actualmente catalogados como deficientes de $\mathrm{GH}$, varios grupos de investigadores han intentado buscar una alteración en la estructura del gen del factor liberador que explique la escasa secreción de dicho factor en estos casos. Sin embargo no han tenido éxito hasta el moment ${ }^{8}$, por lo que no se ha dilucidado aún el mecanismo que interfiere con la secreción de factor liberador en estos pacientes.

Recientemente se ha descrito una mutación en el receptor del factor liberador que causa un severo retraso del crecimiento en una población consanguínea de Pakistán. Como sería de esperar, en estos pacientes no aumentan los niveles de $\mathbf{G H}$ al ser estimulados con factor liberador. Por este motivo se sospechó que su defecto podría residir en el receptor de dicho factor. Como existe un modelo animal (el little mouse) que posee un defecto en dicho receptor que causa un severo retraso del ctecimiento, se estudiaron las regiones génicas que codifican la porción extracelular del receptor del factor liberador en los pacientes de Pakistán y se encontró una mutación en esa zon $a^{9,10}$. Estos pacientes no crecen debido a que el factor liberador no puede ejercer su efecto biologico al interactuar con un receptor defectuoso. Por lo tanto no son candidatos a rratamiento con factor liberador, sino con $\mathrm{GH}$.

Durante los últimos años se ha descubierto que en la regulación de la síntesis y liberación de GH también participaría otro péptido, derivado de la encefalina, péptido liberador de $\mathrm{GH}$ que parece estimular su secreción actuando tanto a nivel hipotalámico como hipofisiario ${ }^{11 .} 12$. Recientemente se han sintetizado varios análogos del péptido liberador de $\mathrm{GH}$ que corresponden a compuestos de origen benzolactátnico ${ }^{13} y$ parecen actuar a través de un receptor distinto al del factor liberador ${ }^{14}$. La importancia de estos nuevos secretagogos de $\mathrm{GH}$ reside en que su mecanismo de acción es diferente al del factor liberador y pueden ejercer su efecto por vía nasal u oral. Desgraciadamente, la GH y el factor liberador no son efectivos por estas vías y deben ser administrados vía parenteral.

Actualmente el péptido liberador y un estimulador benzolactámico de $\mathrm{GH}$ están siendo utilizados en el Instituto de Investigaciones Matemo Infantiles en investigaciones dirigidas a niños deficientes de GH. Dentro de estos proyectos tratamos durante 8 meses con distintas dosis de péptido liberador a 6 niños deficientes de hormona de crecimiento. En ellos se observó un incremento en su velocidad de crecimiento y en las concentraciones promedio de $\mathrm{GH}$ durante la administración de péptido liberador ${ }^{15}$. En caso de ser efectivos durante tratamientos más prolongados, estos nuevos fármacos podrían re- 
volucionar el manejo de los niños con talla baja, ya que podrían constituir una terapia sencilla. de bajo costo y efectiva por vía oral.

\section{Hịpófisis}

Los somatotropos constituyen $50 \%$ de las células de la hipófisis anterior. Para que los somatotropos se diferencien a partir de las células originales de la adenohipófisis, debe actuar un facior de transcripción hipolisiario llamado PIT-I. EI PIT-1 es una proteína responsable de la diferenciación y proliferación no sólo de los somatotropos, sino también de los lactotropos que producen prolactina y de los tireotropos que producen tirolrotina. Se han descrito mutaciones en el gen de este factor de transcripción que sou responsables de severo retraso del crecimiento en niños, causado por acentuadas deficiencias de GH, TSH y prolactina ${ }^{16}$. Estos pacientes muestran crecimiento pobre prenatal $y$ postnatal $e$ importante retraso en la maduración ósea. probablemente debido a la deficiencia combinada de $\mathrm{GH}$ y hormonas tiroideas.

El gen de la GH está localizado en el cromosoma 17 y y es uno de cinco genes que codifican diversas formas de GH relacionadas estructuralmente. La GH-l es el más importante ya que se cxpresa en la glándula pituitaria y da origen a la hormona de crecimiento que circula en el to- rrente sanguíneo, Los otros cuatro genes se expresan en otros tejidos, en especial en la placenta. Entre estos genes existe alta homología, lo que sugiere que derivan de un tronco ancestral común. El gen GH-1 está compuesto de cinco exones (zonas del gen que se traducen) y da origen a dos tipos de GH: GH de 191 aminoácidos en alrededor de $90 \%$ y $\mathrm{GH}$ de 176 aminoácidos en alrededor de $10 \%$. Existen varios defectos moleculares descritos en el gen de la $\mathrm{GH}$. como deleciones mayores o defectos puntuales que tienen diferentes formas de expresión clínica y patrones de herencia. Todos los pacientes con alteraciones del gen de GH muestran disminución muy marcada de la velocidad de crecimiento. Los diversos cuadros clínicos causados por alteraciones en el gen de GH se presentan en la tabla 3.

La GH comenzó a ser utilizada para tratar niños con deficiencia de ella hace aproximadamente 40 años. Inicialmente la hormona utilizada era hipofisiaria. A partir de 1985 se ha utilizado GH sintética, porque en algunos pacientes que usaron $\mathrm{GH}$ de origen pituitario se detectaron casos de demencia tipo Creutzfeld Jacob, después de un largo período de latencia. Ello fue causado probablemente por la contaminación, con el agente de la enfermedad, de las glándulas pituitarias procesadas para obtener GH. La fabricación de GH por ingeniería genética ha eliminado este problena y aumentado la

\section{Tabla 3}

Alteraciones en el gen de la hormona de crecimiento

\begin{tabular}{|c|c|c|c|c|}
\hline Tipo & Herencia & GH endógená & Kespuesta a GH & Defectio molecular \\
\hline \multicolumn{5}{|l|}{ IGHD } \\
\hline IA & Autosómica recesiva. & Ausente & Variable & $\begin{array}{l}\text { Deleción de ambos } \\
\text { alelos del gen de } \mathrm{GH}\end{array}$ \\
\hline$I B$ & Autusómica recesiva & Disminuida & Presente & Mutaciones del gen de GH \\
\hline II & Autosómita dominante & Disninuida & Ptesente & Mutaciones del gen de GH \\
\hline [II & Ligada a $X$ & Disminuida & Presenle & Mutaciones en X \\
\hline \multicolumn{5}{|c|}{ Panbipopituitarismo } \\
\hline I & Autosóntica recesiva & Disminuida & Presente & Algunas mutaciones en PIT-I \\
\hline lB & $\begin{array}{l}\text { Autosomica recesiva o } \\
\text { dominante }\end{array}$ & Ausente & Presente & Algunas mutaciones en PIT-] \\
\hline II & Ligasla a X & Distnintijda & Presente & \\
\hline
\end{tabular}


disponibilidad de la hormona, que se ha comenzado a utilizar en otros problemas clínicos. La indicación más apropiada es en los niños con deficiencia de $\mathrm{GH}$, en quienes se obtiene un incremento en su velocidad de crecimiento desde

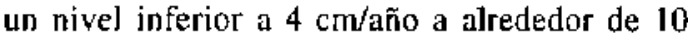
$\mathrm{cm} /$ año durante el primer año de tratamiento, para disminuir algo esta respuesta en los años posteriores ${ }^{17}$. Después de varios años de tratamiento se obtiene una ganancia neta en la estatura final de estos pacientes de alrededor de 15 cm. Tambièn se ha utilizado la $\mathrm{GH}$ en niñas con síndrome de Turner. Varios estudios demuestran aumento sostenido en la velocidad Je crecimiento de estas pacientes durante el tratamiento. En uno la estatura final fue $8 \mathrm{~cm}$ superior a la pronosticada antes de administrar $\mathrm{GH}^{18}$. También se ha intentado mejorar la estatura de niños con talla baja familiar o con talla baja secundaria a retraso de crecimiento intrauterino con $\mathrm{GH}$. En algunos de estos pacientes se han observado mejorías transitorias de su velocidad de crecimiento, pero aún no se ha podido establecer con certeza si el tratamiento mejora la estatura final ${ }^{19.20}$. Cabe mencionar que algunos pacientes pueden desarrollar hipotiroidismo, epifissiólisis o aun hipertensión endocraneana con $\mathrm{GH}$, por lo que este tratamiento debe ser aplicado sólo en casos muy seleccionados bajo un control nuly estricto ${ }^{21,22}$.

Una vez secretada, la GH es transportada por dos proteinas ligantes llamadas GHBP (GH binding proteins). Una de ellas de baja afinidad y alta capacidad y la otra de alta afinidad y baja capacidad. Esta última es la proteína específica, y tiene mayor importancia. La secuencia nucleotídica de la proteína ligadora de alta afinidad es idéntica al dominio extracelular del receptor de GH. Ella parece actuar como reser. vorjo de GH y modula la acción de la hormona sobre sus receptores periféricos. Debido a que su concentración guarda relación con los niveles de receptores en diversos tejidos, es posible obtener información indirecta sobre las concentraciones de receptores tisulares para la $\mathrm{GH}$ midiendo los niveles de su proteína ligadora (GHBP). Probablemente sea necesario medir los niveles circulantes de esta proteína para poder interpretar la suficiencia en la secreción de GH en un paciente con talla baja. Cabe mencionar que existe correlación entre la edad y el estado nutricional de un niño con su concentración de
GHBP, por lo que es muy importante considerar estas variables al medir los niveles de ésta.

\section{Tejidos periféricos}

Cada molécula de GH tiene dos sitios de unión para su receptor, por lo que al unirse la GH al receptor se produce la dimerización de dos receptores como primer paso en el proceso de traducción de la señal. Una vez dimerizado el receptor, se produce la fosforilación de tirosinas intracelulares, proceso catalizado fundamentalmente por una proteinkinasa que pertenece a la familia de kinasas Janus 1lamada JAK2. Esta desencadena la fosforilación de varias proteínas con residuos de tirosina, iniciando una cascada de eventos que conduce a diversos procesos de diferenciación, crecimiento celular y regulación metabólica.

La importancia clínica de las alteraciones del receptor de GH se visualizó hace ya más de 3 décadas cuando Laron ${ }^{23}$ describió los primeros casos de enanismo causado por resistencia a la $\mathrm{GH}$. Estos pacientes muestran severo retraso de crecimiento asociado a un fenotipo caracterizado por frente abombada, fascies infantil, puente nasal bajo, voz aguda y obesidad centripeta (figura 3). Paradojicamente, estos niños poseen altos niveles de $\mathrm{GH}$, pero bajas concentraciones de [GF-1, que es uno de los efectores de GH (figura 2). Por este motivo se sospechó que su defecto podría residit en el receptor de $\mathrm{GH}$, lo que produciría insensibilidad a la acción de esta hormona. Posteriormente se demostraron mutaciones en la zona del gen que codifica para el dominio extracelular del receptor de GH en estos pacientes. Esta zona es idéntica a la proteína ligadora de alta afinidad de GH, que parece originarse por fragmentación proteolítica del receptor. Por este motivo los niveles de la proté́na ligante de alta afinidad tienden a estar bajos en la mayoría de estos pacientes. Sin embargo, recientemente se han identificado otros pacientes con insensibilidad a $\mathrm{GH}$ cuyo defecto no se encuentra en la porción extracelular del receptor, sino en su porción transmembranosa o intracelular, por lo que algunos de ellos pueden tener niveles de proteína ligante normales o aun elevados 24.25 .

Existe una amplia gama de sensibilidad a la $\mathrm{GH}$, causada por distintos niveles de función del 
receptor de $\mathrm{GH}$. Algunos niños con aparente talla baja idiopática poseen concentraciones de proteína ligante de $\mathrm{GH}$ de alta afinidad $y$ de IGF-I disminuidas, asociadas con niveles circulantes de $\mathbf{G H}$ elcvados 26 . Este cuadro es sugerente de insensibilidad parcial a la $\mathrm{GH}$. lo que ha sido confirmado al estudiar la estructura genómica del receptor de GH y encontrar mutaciones que producen insensibilidades parciales a la GH. Estas mulaciones modifican las constanles de afinidad de la proteína ligante y del receptor a la $\mathrm{GH}^{27}$. Estos hallazgos sugieren qu心

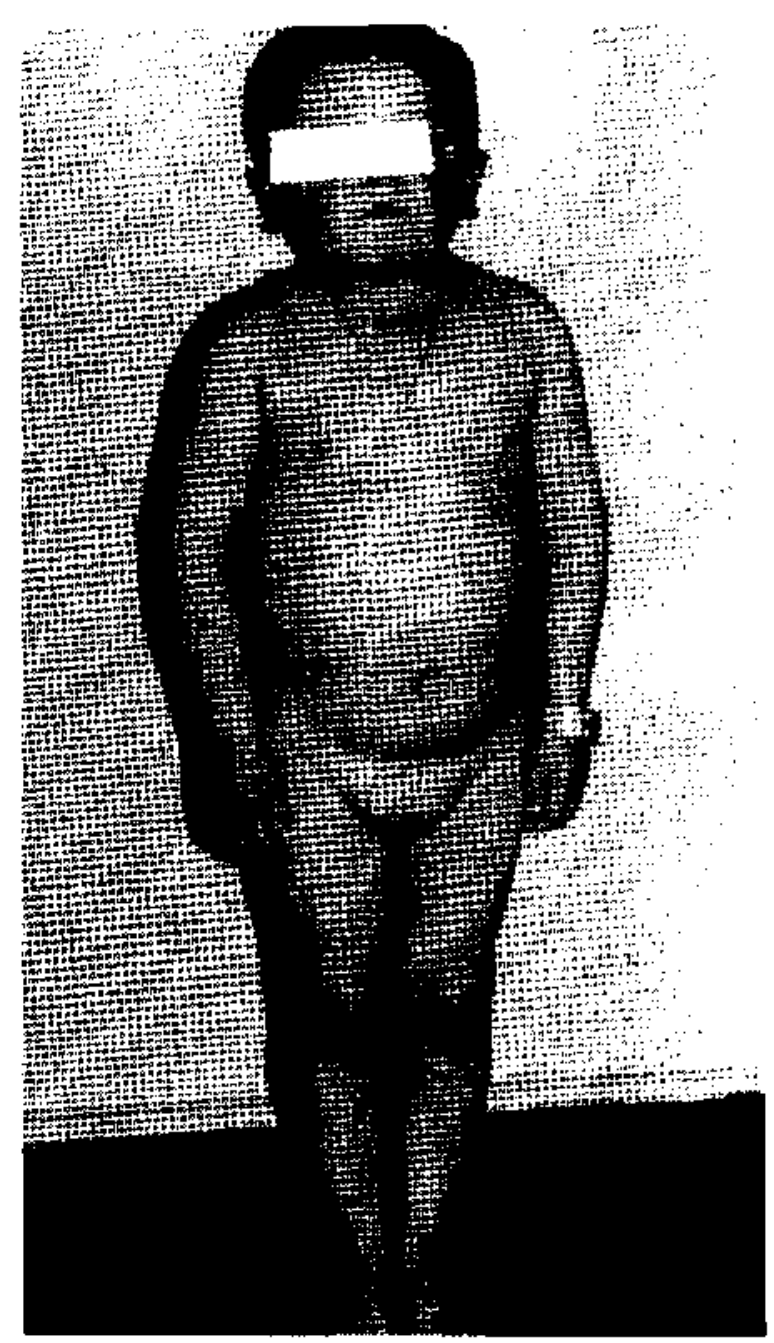

Figura 3: Escolal de 14 años portador de síndrome de Laroti o resistencia a la homona de crecimiento. A esa edad el pacicilte tenía una estatura de $93 \mathrm{~cm}$ y peso de $15.8 \mathrm{~kg}$ algunos niños de baja estatura actualmente catalogados como "idiopáticos" sufren de insensibilidad parcial a la GH, que podría ser corregida con IGF-1. Estos pacientes no serían buenos candidatos a tratamiento con $\mathrm{GH}$ debido a que muestran una resistencia a dicha hormona.

\section{Factores de crecimiento insulino símiles (IGFs)}

Las IGF son factores de crecimiento insulino símiles ( 1 y 2) constituidos por péptidos con una estructura muy semejante a la insulina. Existen dos IGF, la IGF-1 que es un importante mediador de la acción de GH y juega un rol fundamental durante el crecimiento pre y postnatal, mientras la JGF-2 parece ser más importante durante el desarrollo prenatal. In vitro se ha demostrado que las IGF son potentes estimuladores de la proliferación y diferenciación celular, síntesis proteica e inhibición de la apoptosis celular. Por otra parte, in vivo, la IGFl estimula la captación de glucosa, el anabolismo proteico e inhibe la lipólisis. A nivel de la placa epifisiaria, la IGF-1 estimula la diferenciación y multiplicación de los condrocitos, lo que promueve el crecimiento de los huesos largos.

La GH es uno de los principales moduladores de la expresión de IGF-1. Por este motivo la IGF-1 es un marcador muy valioso de la secteción integrada de GH, y la medición de sus concentraciones circulantes es muy útil para establecer el nivel de producción de GH en un niño con talla baja. Sin embargo, debe mencionarse que otros factores también son determinantes para la producción adecuada de IGF-1, tales como un adecuado estado nutricional, y normalidad en la función hepática, renal y tiroidea. Los niveles de IGF-I aumentan desde el nacimiento a la adolescencia y existe un leve dimorfismo sexual con valores algo más elevados en las mujeres. La principal fuente de producción de IGF- 1 es el hígado, aunque existe además una producción local de IGF- 1 en diferentes órganos, to que es consistente con un desempeño iuto o paracrino de este péptido en diversos tejidos. Recientemente se ha descrito el primer caso de talla baja causada por una deleción del 
gen de IGF-1. Este paciente tenía un importante retraso del crecimiento prenatal y postnatal, lo que demuestra que la IGF-1 estimula el crecimiento durante ambas etapas ${ }^{28}$. Asimismo, cabe mencionar que la talla baja de algunos pigmeos africanos parece ser causada por una resistencia a los efectos biológicos de la IGF-1 posiblemente debido a una alteración de sus receptores ${ }^{29}$.

La IGF-2 parece jugar un papel predominante durante el desarrollo prenatal, más que en el crecimiento postnatal. Cabe mencionar que los receptores de IGF-1 e IGF-2 son muy distintos, ya que el receptor de IGF-I posee un alto grado de homología con el de insulina, mientras que el de IGF2 tiene una estructura similar al de manosa 6 fosfato. Debido a la homología entre el receptor de IGF-1 y el de insulina, la IGF-I es capaz de unirse al receptor de insulina y estimular la captación de glucosa por diversos tejidos. En forma inversa, en condiciones clínicas caracterizadas por altos niveles de insulina, el receptor de IGF-1 también puede ser estimulado por dicha hormona. Ello probablemente explica la macrosomía que se observa en los reciên nacidos hijos de madies diabéticas.

Debido a sus variados efectos biológicos, la IGF- $t$ ha sido empleada en clínica en diversas situaciones como el tratamiento de niños con talla baja secundaria a insensibilidad a la $\mathbf{G H}$, el tratamiento de ciertos estados catabólicos, el de algunas hiperglicemias refractarias a la insulina y en afecciones renales cróniças. El tratamiento con IGF-I ha demostrado su utilidad en los ninos con insensibilidad a la $\mathrm{GH}$, pero en otros problemas clínicos su uso es todavía experimental $^{30}$. Una de las experiencias más completas en el uso de IGF-I en niños con insensibilidad a la $\mathrm{GH}$ se ha Jado en el sur de Ecuador, donde algunos de sus habitantes son portadores de una mutación en el receptor de GH. En 16 niños de esta población se utilizó IGF-1 para estimular su crecimiento y se observo que aumentaron su velocidad de crecimiento desde $2,9 \mathrm{~cm} /$ año a

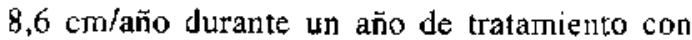
IGF-1 ${ }^{3 !}$. Aún es muy prematuro para establecer el efecto del tratamiento con IGF-1 sobre la estatura final de estos pacientes, pero es muy probable que el péptido sea útil para tratar niños con insensibilidad a la $\mathrm{GH}$, y potencialmente en otras enfermedades.

\section{Proteínas ligantes de los factores de crecimiento insulino símiles}

En el plasma y en los tejidos las IGF están unidas a proteínas ligantes específicas. El hígado es el más importante órgano productor de estas proteínas y ellas comparten una alta homología estructural. Hasta el momento se han identificado seis proteínas ligantes de IGF y sus funciones aparentemente incluyen: transportar los factores de crecimiento en el plasma, prolongar la vida media de las IGF, modular la interacción de las IGF con sus receptores y potencialmente producir efectos directos sobre algunos procesos celulares independientes.

De las proteínas ligantes, la más relacionada con los riveles circulantes de GH es la IGFBP-3, que junto a la unidad ácido lábil y la IGF-I forma un complejo de $150 \mathrm{KD}$ que circula en el compartimento vascular. Aproximadamente $80 \%$ de la IGF-1 circula en esta forma. $y$ la concentración de este complejo es dependiente de la concentración circulante de GH. Cabe mencionar que los niveles de este complejo van aumentando con la edad, lo que es especialmente notorio durante la pubertad ${ }^{32}$. Como los niveles circulantes de IGFBP-3 son dependientes de $\mathrm{GH}$, esta proteína ligadora es, junto con la IGF-1, un excelente marcador periférico de la secreción integrada de $\mathrm{GH}$, lo que ha simplificado mucho la evaluación de un niño con talla baja. Actualmente, es posible medir los niveles circulantes de IGF-1 e IGFBP-3 en una sola muestra de sangre que permite evaluar la producción de $\mathrm{GH}$, y se pueden reservar las molestas pruébas de estímulo para $\mathrm{GH}$ sblo para aquellos pacientes que poseen niveles marginales de IGF-1 e IGFBP-3?. De las otras proteinas ligantes, sólo la IGFBP-2 parece ser útil en Ja evaluación de los pacientes con talla baja, ya que sus niveles circulantes están paradójicamente aumentados en los niños con deficiencia de $\mathrm{GH}^{33}$.

En este artículo hemos tratado de describir en forma comprensible para el pediatra general los nuevos conocimientos acerca del eje hommona del crecimiento-efector y cómo pueden ser aplicados al estudio del niño con talla baja. Cabe mencionar que algunos trastornos que se han observado en grupos muy especiales de niños ubicados en diferentes partes del mundo, pueden también afectar en forma más sutil a algunos pacientes catalogados como portadores de 
talla baja idiopática. Ello ha expandido nuestro diagnóstico diferencial en el estudio del niño con estatura baja y demuestra la importancia de cada elemento que participa en este sistema hormonal. Todas estas hormonas, junto con un optimo estado de salud, adecuada nutrición y a un positivo ambiente sicosocial, van a permitir la expresión del potencial genético de crecimiento de cada individuo.

\section{Referencias}

I. Guillemin R. Brazeat P, Bohlen $P$, et al: Growth hormone-releasing factor from a human pancreatic tumor that caused acromegaly. Science 1982:218: 585587.

2. Tussmi $P$, Cucciari $E$, Cau $M$, et al: Variability of growth hormone response to pharmacological and sleep tests performed twice in short children. J Clin Endocrinol Metab 1990: 71: 230-234.

3. Rosenfeld $R$. Albertsson-Wikland $K$, Cassosta $F$, et al: Diagnostic controversy: The diagnosis of childhood growth hormone deficiency revisited. I Clin Endocrinol Metab 1995: 80: 1532-1540.

4. Frohman LA, Downs TR, Chonczynski P, et at: Growth hormone relessing hormone: structure, gene expression and molecular heterogeneity. Acta Pediatr Scand 1990; (suppl) 367: 81-86.

5. Schriock EA. Lustig RH. Rosentital SM. Kaplar SL, Grumbach MA: Effect of growth hormone (GH)releasing hormone (GRH) on plasma $\mathrm{GH}$ in relation to magnitude and duration of $G H$ deficiency in 26 children and adults with isolated $\mathbf{G H}$ deficiency or multiple hormone deficiencies; evidence for hypothalamic GRH deficiency. J Clin Endocrinol Metab 1984: 58: 1043-1049.

6. Thorter $M$. Rochicciols P. Colle M. et at: Once daily subcucaneous growth hormone-releasing hormone therapy accelerates growth in growth hormonedeficient children during the first year of therapy. J Clin Endocrinol Metab 1996; 81: 1189-1196.

7. Cussorla $F$, Mericg $V$, Garcia $H$, ef al: The effects of $B 1$ adrenergic blockade on the growth response to grow'tl hormone $(\mathrm{GH})$-relensing hormone therapy in $G \mathrm{H}$ deficient children. $\mathrm{J}$ Clin Endocrimol Metab 1995 : 80: 2997-3001.

8. Pere? Jurado $L A$, Phillips lil JA, Frattcke $U$ : Exclusion of growth hornone releasing hormone gene metations in familiar isolated growth hormone deftciency by linkage and single strand conformation analysis. J Clin Endocrinol Melab 1994; 78: 622-628.

9. Wainrajch $M T$. Gertner JM, Harbison M.D. ef at Nonsense mutation in the human growth hornonereleasing hormone receptor causes growith failure analogous to the little (lit) mouse. Natare Genetics 1996; 10. 8-90.

10. Muherhuari $H$, Silvesman BL, Dupuis J, et al: Dwarfism of Sindh: a novel fortn of familiar isolated GH deficiency linked to the locus for the $\mathrm{GH}$ releasing hornone receptor. I0th Intemational Congress of
Endocrinology, San Francisco, Junio 1996, (Abstract $\left.N^{2} \mathrm{OR} 46-2\right)$.

11. Bowers CY. Sartor AO. Reynolds GA, et al: On the actions of the growth hormone releasing peptide GHRP. Endocrinology 1991; 128: 2027-2035.

12. Mericq V. Cassoria F. Garcia H. et al: Growth hormone (GH) responsos to $\mathrm{GH}$-releasing peptide and to GH-releasing hormone in GH-deficient children. J Clin Endocrinol Metab 1995; 80; 1681-1684.

13. Gerfz BJ. Barret JS. Eisenihauller R, et al: Grow1h hormone response in man to L-692-429 a novel non peptide mimic of growth hormone releasing peptide. J Clin Endocrinol Metab 1993; 77: 1393-1397.

14. Howard AD. Feighner $\$ D$, Cally FD. et al: A receptor in pituitary and hypothalamus that functions in growth hormone release. Science 1996; $273 ; 974-923$.

15. Mericy V. Cassorla $F$, Soluzar $T$, et al: Increased growth velocity during prolonged GHRP-2 administration to growth hormone deficient children. Annual Meeting of the Endocrine Society, Washington DC. Junio 1995. (Abstract N OR30-3).

16. Li $S$, Crenshaw $L i$ il EB, Rawson $E$ J, et al: Dwarf locus mutants lacking three pituitary cells types result from mutations in the POU domain gene PIT.I. Nature 1990: 347: $528-533$

17. Frasier SD: Human pituitary growth hocmone (hGH) therapy in growth hormone deficiency. Endoct Rev I983: 4: 155-210.

18. Rosenfeld RG, Frane J, Attie $K M$, et al: Six year old results of a randomized prospective trial of human growth hormone and oxandrolone in Turner syndrome. J Pediarr 1992; 121:49-55

19. Luche $S$, Cambiaro $P$, Setzu $S$, et al: Final height after growth hormone therapy in non - growth hormone deficient chuldren. J Pedialr 1994; 125: 196-200.

20. Albertssun Wikland $K$ : Growth hormone treatnent in shon children: short term and long term effects on growth. Acta Paediatr Scand (suppl) 1988; 343: 77-84.

2I. The Lawson Wilkins Pediatric Endocrine Society. Safety of human growth hormone therapy. Horm Res 1993: 39: 94-108.

22. A report by the Drug and Therapeutics Committee of the Lawson Wilkins Pediatric Endocritne Society. Guidelines for the use of growth hormone in children with short slature. J Pediatr 1995; 127: 857-867.

23. Liron $Z$ : Laron syndrome: from description to therapy. The Endocrinologist 1993; 3: 21-28.

24. BuchananCR, Maheshwiri $H G$. NormanMR, et al: Laron type dwarfism with apparently normal high affinity serum growth hormone binding protein. Clin Endoctinol 1991: 35: 179-185.

25. Ko K, Lajara $R$, Roru'ein P: Amino acid subtitutions in the intracellular pat of the growth hormone recep. tor in a patient with the Laron syndrome. J Clin Endocrinol Metab 1993; 76 : $54-59$.

26. Antie KM, Carlsson LMS. Rundie $A C$, et at: Evidence for partial growth hornone insensitivity arnong palienrs with idiopathic short stature. J Pedjatr J995: 127: $244-250$.

27. Godederd AD. Covello R. Luoh SM, et al: Mutations of the growth hormone receptor in children with idiopathic short stature. N Engl J Med 1995; 333: 10931098. 
28. Woods KA, Camacho-Hubner C, Savage MO et al: Intrauterine growth retardation and postnatal growth failure associated with deletion of the insulin-like growth factor 1 gene. N Engl J Med 1996; 335: 136.31367.

29. Humeri Y, Vera JC, Coralia IR, et at; Decreased insulin-like growth factor 1 receptor expression and function in inmortalizad African pygmy T cells. J Clin Endocrinol Metab 1996; 81: 2257-2263.

30. Clemnirms $D$, Undernowd LE: Uses of human insulin like growth factor $I$ in clinical conditions. J Clin Endocrino: Metab 1994: 79: 4-7.
31. Guevara-Aguirre J, Vasconez $O$, Martinez $V$, et al: A randomized, double blind, placebo controlled trial on safety and efficacy of recombinant human insulin-like growth factor-I in children with growth hormone receptor deficiency. I Clin Endocrinol Metab 1995; 80: 1393.1398.

32. Blan W. Ranke $M$ : Modern concepts of insulin like growth factors. EM Spencer, Ed Elsevier, New York 1991; $381-393$.

33. Jones $f$ Clemmons $D$ : Insulin like growth factor and their binding proteins: biological actions. Endoce Rev 1995; 16: 3-25.

\section{AVISO A LOS AUTORES}

Con el abjeto de dar prioridad a los trabajos de investigacion, en vista de las limitaciones de espacio de la Revista Chilena de Pediatría, el Comité Editorial ha acordado restringir la impresión de casos clínicos a un máximo de dos por cada número. 